\title{
Aminoguanidine inhibits semicarbazide-sensitive amine oxidase activity: implications for advanced glycation and diabetic complications
}

\author{
P.H. Yu, D.M. Zuo \\ Neuropsychiatry Research Unit, Department of Psychiatry, University of Saskatchewan, Saskatoon, Saskatchewan, Canada
}

\begin{abstract}
Summary Aminoguanidine, a nucleophilic hydrazine, has been shown to be capable of blocking the formation of advanced glycation end products. It reduces the development of atherosclerotic plaques and prevents experimental diabetic nephropathy. We have found that aminoguanidine is also quite potent at inhibiting semicarbazide-sensitive amine oxidase (SSAO) both in vitro and in vivo. The inhibition is irreversible. This enzyme catalyses the deamination of methylamine and aminoacetone, which leads to the production of cytotoxic formaldehyde and methylglyoxal, respectively. Serum SSAO activity was reported to be increased in diabetic patients and positively correlated with the amount of plasma glycated haemoglobin. Increased SSAO has also been demonstrated in diabetic animal models. Urinary excretion of methylamine is substantially increased in the rats following acute or chronic treatment with aminoguanidine. Urinary methylamine levels were substantially increased in streptozotocin (STZ)-induced diabetic
\end{abstract}

rats following administration of aminoguanidine. The non-hydrazine SSAO inhibitor (E)-2-(4-fluorophenethyl)-3-fluoroallylamine hydrochloride (MDL72974A) has been shown to reduce urinary excretion of lactate dehydrogenase (an indicator of nephropathy) in STZ-induced diabetic rats. Formaldehyde not only induces protein crosslinking, but also enhances the advanced glycation of proteins in vitro. The results support the hypothesis that increased SSAOmediated deamination may be involved in structural modification of proteins and contribute to advanced glycation in diabetes. The clinical implications for the use of aminoguanidine to prevent glycoxidation have been discussed. [Diabetologia (1997) 40: 1243-1250]

Keywords Aminoguanidine, methylamine, formaldehyde, semicarbazide-sensitive amine oxidase (SSAO), SSAO inhibitor, diabetes, advanced glycation, glycoxidation, streptozotocin.
Glucose reacts chemically with the amino groups of amino acids or nucleic acids to form Amadori products [1], which then rearrange into advanced glycation end products (AGEs) [2]. This process leads to

Received: 8 May 1997 and in revised form: 24 June 1997

Corresponding author: Dr. P. H. Yu, Neuropsychiatry Research Unit, Department of Psychiatry, University of Saskatchewan, Saskatoon, Saskatchewan, S7N 5E4 Canada

Abbreviations: SSAO Semicarbazide-sensitive amine oxidase; STZ streptozotocin; AGEs advanced glycation end products; LDH lactate dehydrogenase; LDL low density lipoprotein; MDL-72974A (E)-2-(4-fluoro-phenethyl)-3-fluoroallylamine hydrochloride. marked changes in the structure and function of various proteins. The formation of AGEs from the Amadori product is also known to occur via an oxidative process [3]. It is accelerated in the presence of transition metals and is reduced by ascorbate $[4,5]$, suggesting that the reaction is mediated by free radicals [6]. There is accumulating evidence that the formation of AGEs increases with aging [7] and is implicated in the pathogenesis of diabetic atherosclerosis [2]. AGEs can crosslink with collagen and other structural and functional proteins [1]. This increases the rigidity of collagen, decreases arterial compliance, and enhances hypertension [8,9]. Advanced glycated collagen is capable of covalently trapping LDL [10]. LDL, once trapped in the arterial wall, is susceptible 
to attack by free radicals and subject to oxidative modification [11]. AGEs may also affect monocyte migration and induce an inflammatory response [12, 13].

Aminoguanidine reacts with Amadori fragmentation products and thus prevents glycation and AGE formation [14]. It prevents experimental diabetic nephropathy [15] and inhibits lipid peroxidation in vivo [16]. It also blocks the oxidative modification of LDL and its subsequent uptake by macrophages in a euglycaemic in vitro system [17]. The drug can reduce the development of atherosclerotic plaque without altering serum cholesterol levels in cholesterol-fed rabbits [18], urinary albumin excretion in diabetic rats $[19]$ and regional albumin clearance [20].

Aminoguanidine is a nucleophilic hydrazine. It is well known that hydrazine compounds are capable of interacting with carbonyl groups of different biological constituents, such as glucose, pyridoxal, 6-hydroxydopa and pyrroloquinolinone quinone enzyme cofactors, etc. SSAO is an enzyme that possesses 6hydroxydopa as a cofactor, and is quite sensitive to hydrazines. We therefore investigated whether aminoguanidine inhibits SSAO activity. This enzyme catalyses the deamination of methylamine, for example, and produces toxic formaldehyde and hydrogen peroxide $[21,22]$. Serum SSAO activity has been found to be substantially increased in diabetes and patients with liver diseases [23-26]. A significant positive correlation between SSAO activities and plasma glycated haemoglobin levels was observed [26]. SSAO activity has also been found to be increased in the blood and kidney of diabetic rats (streptozotocin [STZ]-treated) [27] and diabetic sheep (alloxantreated) [28]. Deamination of methylamine by serum SSAO is cytotoxic to endothelial cells in vitro and SSAO inhibitors block this toxicity [29]: It has been proposed that excessive deamination of methylamine may be involved in the initiation of endothelial injury and be related to diabetic complications [29]. In the present study we describe the inhibition of SSAO by aminoguandine and the possible involvement of SSAO in advanced glycation. Alternative actions of aminoguanidine are discussed.

\section{Materials and methods}

Materials. Human umbilical cords were kindly provided by the Department of Obstetrics and Gynecology, Royal University Hospital, Saskatoon. Benzylamine, aminoguanidine bicarbonate, methylamine hydrochloride, horseradish peroxidase, 3 (4,5-dimethylthiazol-2-yl)-2,5-diphenyl tetrazolium bromide and semicarbazide hydrochloride were purchased from Sigma, (St. Louis, Mo., USA). $\left[7-{ }^{14} \mathrm{C}\right]$-Benzylamine, $\left[{ }^{14} \mathrm{C}\right]-$-methylamine and [methyl- $\left.{ }^{3} \mathrm{H}\right]$-thymidine were obtained from Amersham (Oakville, Ontario, Canada). (Clorgyline [N-(2, 4-dichlorophenoxy-n-propyl)-N-methylpropargylamine $\mathrm{HCl}]$ and (E)-2-(4-fluorophenethyl)-3-fluoroallylamine hydrochloride
(MDL-72974A) were gifts from May and Baker Ltd. (Dagenham, UK) and Merrell-Dow Research Institute, Cincinnati, Ohio, USA), respectively. All other chemicals were of analytical grade.

Animal experiments. Male Wistar rats $(200 \mathrm{~g})$ were used in the experiments. The animal treatments were in strict accordance with the guidelines established by the Canadian Council on Animal Care and were approved by the University of Saskatchewan Animal Care Committee. The rats were housed in hanging wire cages with free access to food and water on a $12 \mathrm{~h} \mathrm{light/dark}$ cycle (lights on 06.00 hours) at a temperature of $19-20^{\circ} \mathrm{C}$. Diabetes was induced in animals by a single administration of STZ $(60 \mathrm{mg} / \mathrm{kg}$, i.p.). Serum glucose levels were assessed in order to ensure that diabetes was induced. The blood glucose levels of the control and STZ-induced diabetic rats were $1.61 \pm 0.04$ (mean $\pm S E M$ ) and $4.74 \pm 0.35 \mathrm{mg}$ / $\mathrm{ml}$ (from 3.3 to $7.5 \mathrm{mg} / \mathrm{ml}$ ) respectively. Aminoguanidine $(10 \mathrm{mg} / \mathrm{kg}$ ) was administered daily via intraperitoneal injection for 3 weeks. The aminoguanidine treatment was then maintained by including the drug in the drinking water $(1 \mathrm{mg} / \mathrm{ml})$. The control animals were injected with saline and supplied with tap water. Twenty-four-hour urine was collected with metabolic cages at $24 \mathrm{~h}, 1$ week, 3 week and 7 weeks after the initial aminoguanidine treatment.

Preparation of SSAO from rat aorta and human umbilical artery. SSAO from human umbilical artery [29] and rat aorta [30] was prepared as previously described. Tissues were thoroughly rinsed with saline, sliced into small pieces and homogenized with a Polytron homogenizer (PT-10-35, at setting 5 for four periods of $5 \mathrm{~s}$ on ice) in chilled $0.01 \mathrm{~mol} / \mathrm{l}$ phosphate buffer ( $\mathrm{pH} \mathrm{6.8).} \mathrm{The} \mathrm{crude} \mathrm{homogenates} \mathrm{were} \mathrm{centrifuged} \mathrm{at} 800 \mathrm{~g}$ for $10 \mathrm{~min}$ and the supernatants further centrifuged at $32000 \mathrm{~g}$ for $30 \mathrm{~min}$. These final supernatant enzyme preparations were either used immediately or stored at $-70^{\circ} \mathrm{C}$. The enzymes were quite stable under these conditions for at least 1 month.

Determination of SSAO activity. SSAO activity was determined by a radio-enzymatic procedure using ${ }^{14} \mathrm{C}$-labelled benzylamine as substrate following our previously described procedure [29]. The SSAO enzyme preparations were pre-incubated with clorgyline $\left(1 \times 10^{-4} \mathrm{~mol} / \mathrm{l}\right)$ at room temperature for $20 \mathrm{~min}$ to ensure that any monoamine oxidase activity, if present, was completely inactivated. The enzyme was then incubated in the presence of benzylamine $\left(5 \times 10^{-5} \mathrm{~mol} / \mathrm{l}, 0.1 \mu \mathrm{Ci}\right)$ in a final volume of $200 \mu \mathrm{l}$ at $37^{\circ} \mathrm{C}$ for $30 \mathrm{~min}$. The enzyme reaction was terminated by adding $200 \mu \mathrm{l} 2 \mathrm{~mol} / \mathrm{l}$ citric acid. The oxidized products were extracted into $1 \mathrm{ml}$ toluene:ethyl acetate $(1: 1, v / v)$, of which $600 \mu \mathrm{l}$ was then transferred to a counting vial containing $10 \mathrm{ml}$ Omnifluor cocktail (New England Nuclear, Boston, Mass., USA). Radioactivity was assessed by liquid scintillation counting (Beckman LS-7500, Fullerton, Calif., USA). One unit of enzyme activity is defined as one nanomole of product formed per min per $\mathrm{mg}$ of protein.

Determination of methylamine. Urinary methylamine was determined using an HPLC-fluorometric procedure. Isopropylamine was added as an internal standard to the urine immediately after its collection and the samples were stored at $-70^{\circ} \mathrm{C}$ until use. Urine samples $(0.5 \mathrm{ml})$ were pre-purified by application to a small column of CG-50 amberlite $(0.5 \times 2.5 \mathrm{~cm})$, rinsed with $10 \mathrm{ml}$ water and the amines then eluted with $2 \mathrm{ml}$ $1 \mathrm{~mol} / \mathrm{l} \mathrm{HCl}$. The samples $(100 \mu \mathrm{l})$ were derivatized with ophthaldialdehyde (OPA) $(100 \mu \mathrm{l})$ under alkaline conditions ( $\mathrm{pH} 10.4$ ), and $50 \mu \mathrm{l}$ of the derivatized sample eluates were separated in a Shimadzu HPLC system (Sil-9A auto injector; 
Tokyo, Japan) equipped with a pre-column derivatization program. The fluorescent amine derivatives were separated in an analytical Ultrasphere I.P. column packed with octadecylbonded spherical-5 micron silica particles $(250 \times 4.6 \mathrm{~mm}$ internal diameter) (Beckman, Toronto, Ontario, Canada). The column was eluted with $55 \%$ methanol at a flow rate of $1.0 \mathrm{ml} /$ min using a SSI 222B solvent delivery system (State College, Pa., USA). For quantitative assessment, a programmable fluorescence detector (Hewlett Packard, HP1046A, Mississauga, Ontario, Canada) with excitation at $360 \mathrm{~nm}$ and emission at $445 \mathrm{~nm}$ was employed. The signals of peak area were integrated using a Spectra-Physics SP-4290 integrator. The retention times for methylamine and iso-propylamine are 11.9 and $29.2 \mathrm{~min}$, respectively. The recovery of methylamine from the ion exchange chromatography was approximately $80 \%$. The peak ratios of methylamine/isopropylamine (internal standard) were used for the calculation of urine levels of methylamine.

Determination of urinary $L D H$ activity. The assay is based on the production of $\mathrm{NADH}$ from nicotinamide adenine dinucleotide $\left(\mathrm{NAD}^{+}\right)$during the conversion of lactate to pyruvate by LDH. NADH was measured spectrophotometrically at 340 nm. AII assays were performed in 96-well plates. An aliquot of urine $(50 \mu \mathrm{l})$ was incubated in the presence of $50 \mu \mathrm{NAD}^{+}$ $(1 \mathrm{mg} / \mathrm{ml})$ and $100 \mu \mathrm{l}$ lactate $(1 \%)$ in $0.05 \mathrm{~mol} / \mathrm{l}$ phosphate buffer, $\mathrm{pH}$ 9.0. The rates of NADH formation (milli-optical density per $\min [\mathrm{mOD} / \mathrm{min}]$ ) were monitored using a UVmax kinetic microplate reader (Molecular Devices, Menlo Park, Calif., USA).

Protein glycation in vitro. In vitro glycation was estimated according to Edelstein and Brownlee [14]. The glycation reactions were conducted at $37^{\circ} \mathrm{C}$ in $0.08 \mathrm{~mol} / 1$ sodium phosphate buffer (pH 7.8) containing $0.12 \mathrm{mg} / \mathrm{ml}$ penicillin-G, $0.1 \mathrm{mg} / \mathrm{ml}$ gentamicin, $0.25 \mu \mathrm{g} / \mathrm{ml}$ fungazone, $0.02 \mathrm{mg} / \mathrm{ml}$ polymyxin $\mathrm{B}, 1 \mathrm{mmol} / \mathrm{l}$ EDTA and $1 \mathrm{mmol} / \mathrm{l}$ phenylmethylsulphonyl fluoride. RNase $(10 \mathrm{mg} / \mathrm{ml})$ was incubated for different time periods with $0.5 \mathrm{~mol} / 1$ glucose in the presence or absence of formaldehyde $(0.005 \%)$. AGE formation was determined fluorospectrometrically at an excitation-emission wavelength of $370 / 450 \mathrm{~nm}$.

Statistical analysis. The results were assessed using analysis of variance (ANOVA) followed by Newman-Keuls multiple comparisons. In general, the null hypothesis used for all analyses was that the factor has no influence on the measured variable and significance was accepted at the over $95 \%$ confidence level.

\section{Results}

Inhibition of SSAO activity by aminoguanidine in vitro. As can be seen from Figure 1, aminoguanidine is quite potent at inhibiting the activities of SSAO obtained from both human umbilical arteries and rat aortae. The $\mathrm{IC}_{50}$ values were estimated to be $1 \times 10^{-5}$ and $2 \times 10^{-5} \mathrm{~mol} / 1$ with respect to the rat aorta and the human umbilical enzymes.

Effect of aminoguanidine on rat kidney and aorta $S S A O$ in vivo. The SSAO activity in rat kidney and aorta was determined $3 \mathrm{~h}$ after a single injection of various doses of aminoguanidine. As can be seen from Figure 2, SSAO activity is significantly inhibited by the drug in both tissues. The $\mathrm{ED}_{50}$ values were
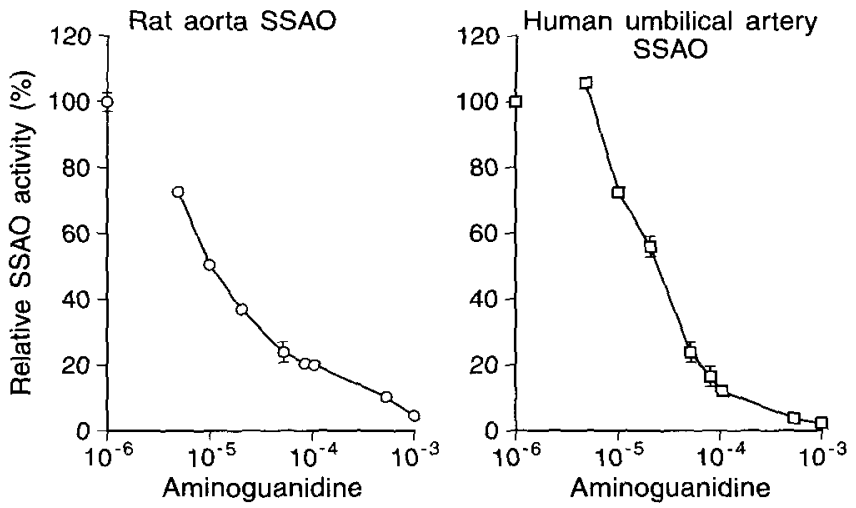

Fig. 1. Inhibition of the activities of SSAO obtained from both human umbilical arteries and rat aortae by aminoguanidine. Enzyme activities were measured by a radioenzymatic method using benzylamine $\left(1 \times 10^{-4} \mathrm{~mol} / \mathrm{l}\right)$ as substrate. The specific activities of the untreated control enzymes were $0.38 \pm 0.03$ and $1.25 \pm 0.02\left(\mathrm{nmol} \cdot \mathrm{min}^{-1} \cdot \mathrm{mg}\right.$ protein $\left.{ }^{-1}\right)$ for rat aorta and human umbilical artery SSAO respectively. The enzymes were pre-incubated in the absence or presence of different concentrations of aminoguanidine for $20 \mathrm{~min}$ at room temperature before addition of substrates
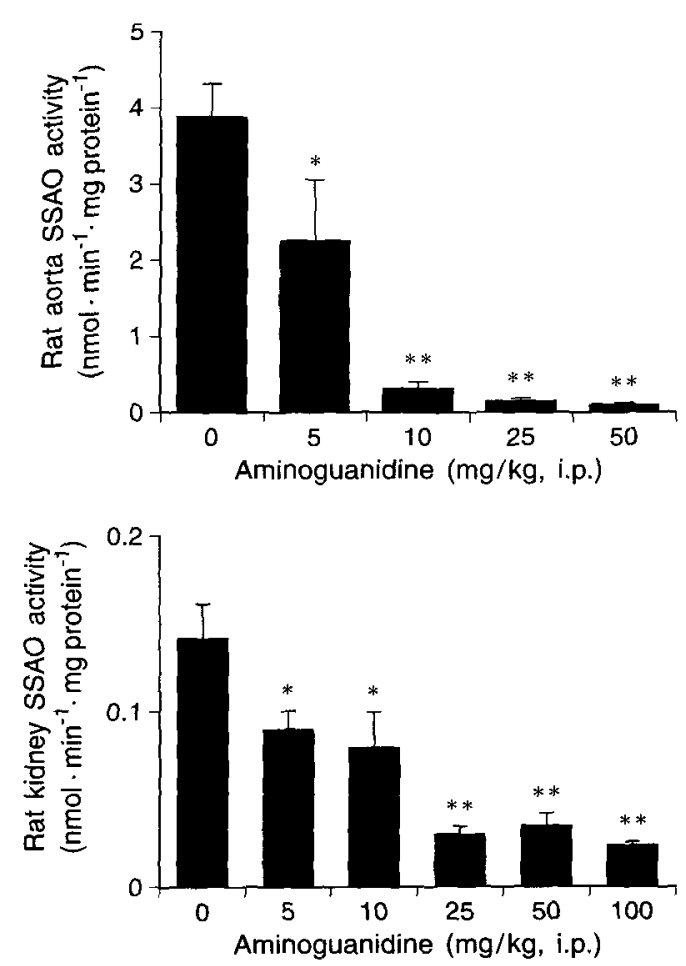

Fig. 2. Inhibition of aminoguanidine on rat kidney and aorta SSAO activity in vivo. Rat kidney and aorta tissues were collected $3 \mathrm{~h}$ after the intraperitoneal administration of different doses of aminoguanidine. Values are mean \pm SEM of three animals at each dose. ${ }^{*} p<0.05, * * p<0.01$

estimated to be 10 and $5 \mathrm{mg} / \mathrm{kg}$ i.p. injection for the rat kidney and aorta SSAO, respectively.

Mode of inhibition of human umbilical SSAO by aminoguanidine. The inhibition of human umbilical 
SSAO activity by aminoguanidine was quite fast. Approximately $90 \%$ of the activity was inhibited without preincubation of the enzyme with aminoguanidine; complete inhibition could be obtained with a $15 \mathrm{~min}$ preincubation. After incubation of the enzyme with aminoguanidine for $30 \mathrm{~min}$, the unreacted inhibitor was removed by gel filtration through a small Sephadex G-25 column (PD-10, Pharmacia). SSAO activity was not recovered after the gel filtration. Untreated SSAO activity was recovered after the same procedure, thus indicating that the inhibition of SSAO activity by aminoguanidine is irreversible.

Effect of aminoguanidine on methylamine excretion. A single dose of aminoguanidine $(25 \mathrm{mg} / \mathrm{kg})$ was administered to rats and the total urine excreted during the following $24 \mathrm{~h}$ collected. The level of methylamine, a typical SSAO substrate, in the urine, was significantly increased. The urinary level of methylamine after treatment with aminoguanidine is quite comparable to that from animals treated with the potent selective SSAO inhibitor MDL-72974A (2 mg/ kg) [29] (Fig. 3).

Chronic effect of aminoguanidine on methylamine excretion in control and diabetic rats. As can be seen from Figure 4 the urinary excretion of methylamine substantially increased at 1,3 and 7 weeks after chronic aminoguanidine treatment in both control and diabetic rats. The increase ranged from 5- to $10-$ fold based on either total methylamine excretion $\cdot 24^{-1} \cdot$ rat $^{-1}$ (Fig. 4, upper panel) or per mg creatinine (Fig. 4, lower panel). The magnitude of increase of methylamine excretion was much more pronounced following chronic treatment than a single acute treatment (Fig.3), indicating that multiple treatments with aminoguanidine may produce cumulative and complete inhibition of SSAO activity.

The total methylamine excretion was slightly increased in the STZ-induced diabetic rats without aminoguanidine treatment (but only significant at 7 weeks). When SSAO activity was blocked by aminoguanidine, however, the methylamine levels were significantly higher in the STZ-induced diabetic rats at different time following aminoguanidine treatment. There was a trend toward further increase of methylamine excretion in the diabetic animals with prolonged illness.

Effect of chronic treatment of SSAO inhibitor on the urinary excretion of $L D H$. Urinary $\mathrm{LDH}$ has been used as a marker of nephropathy [31]. As can be seen from Table 1 its activity was not detected in the control rats, but became detectable by the fourth week and further increased by week 12 in STZ-induced diabetic rats. MDL-72974A was found to reduce the urinary excretion of LDH after 4 weeks of

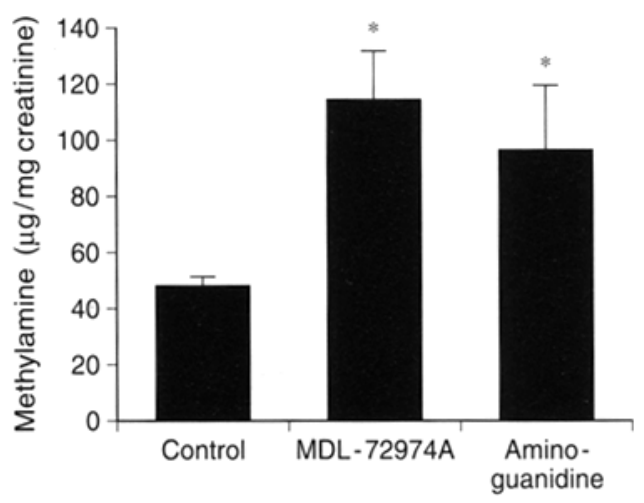

Fig. 3. Effect of aminoguanidine and the selective SSAO inhibitor MDL-72974A on urinary methylamine levels in rats. Aminoguanidine (25 mg/kg), MDL-72974A (2 mg/kg) and saline were administered i. p. to rats and then $24 \mathrm{~h}$ urine was collected. Methylamine was assessed by an HPLC-fluorometric procedure as described in Methods. Creatinine was determined using the picric acid method. Values are mean \pm SEM of three animals at each dose; ${ }^{*} p<0.01$
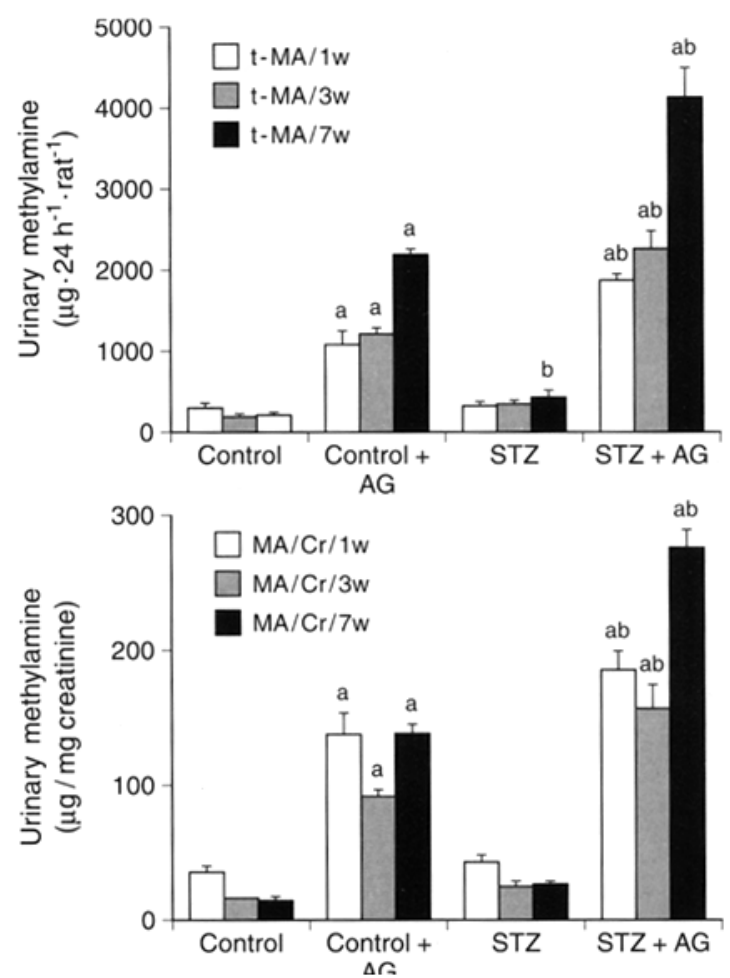

Fig.4. Subchronic effect of aminoguanidine (AG) on urinary methylamine levels in diabetic and control rats. Aminoguanidine $\left(10 \mathrm{mg} \cdot \mathrm{kg}^{-1} \cdot \mathrm{day}^{-1}\right)$ and saline were administered i.p. daily to rats for 3 weeks. The animals were continuously orally treated with aminoguanidine (i.e. the drug was included in the drinking water $[1 \mathrm{mg} / \mathrm{ml}])$. Twenty-four $\mathrm{h}$ urine was collected in $0.05 \mathrm{~N} \mathrm{HCl}$ at 1 week and 3 and 7 weeks after aminoguanidine treatment. Internal standard isopropylamine was added to each sample and the urine was kept frozen at $-70^{\circ} \mathrm{C}$ until assay. Methylamine was assessed by an HPLC-fluorometric procedure as described in Methods. Creatinine was determined using the picric acid method. Values are mean \pm SEM of six animals in each group; a) significantly different from the corresponding aminoguanidine untreated controls; b) significantly different from the corresponding non-diabetic controls 
Table 1. Effect of SSAO inhibitor (MDL-72974A) on STZ-induced nephropathy

\begin{tabular}{llll}
\hline Treatment & \multicolumn{3}{l}{ mU LDH activity/mg creatinine } \\
\cline { 2 - 4 } & Week 1 & Week 4 & Week 12 \\
\hline Control $(n=9)$ & 0 & 0 & 0 \\
MDL-72974A $(n=9)$ & 0 & 0 & $2.22 \pm 0.3^{\mathrm{a}, \mathrm{b}}$ \\
STZ $(n=9)$ & 0 & $0.43 \pm 0.08^{\mathrm{a}}$ & $5.73 \pm 1.44^{\mathrm{a}}$ \\
MDL-72974 + STZ $(n=9)$ & 0 & $0.15 \pm 0.02^{\mathrm{a}, \mathrm{b}}$ & $4.48 \pm 0.32^{\mathrm{a}}$ \\
\hline
\end{tabular}

STZ-induced diabetic rats were either injected with MDL72974A ( $2 \mathrm{mg} / \mathrm{kg}$, i. p.) or saline every second day. Similar saline injections were also given to non-diabetic control animals. At the end of weeks 1,4 and 12 , a $24 \mathrm{~h}$ urine was collected from each animal. The assay of LDH activity is described in the Methods. ${ }^{a} p<0.01$, in comparison to controls; ${ }^{b} p<0.025$ in comparison to STZ group. Number of experimental animals indicated in parentheses. Statistics were performed using twoway ANOVA followed by Newman-Keuls multiple comparisons

treatment in the diabetic rats. MDL-72974A alone was, however, also shown to increase the urinary $\mathrm{LDH}$ in the rats following 12 weeks of chronic treatment. MDL-72974A does not affect blood glucose (result not shown).

Effect of formaldehyde on protein glycation in vitro. Bovine RNase was incubated with glucose in the absence or presence of a small amount of formaldehyde $(0.008 \%)$. The degree of advanced glycation was monitored on different days. As shown in Figure 5, formaldehyde induced a twofold increase in advanced glycation, while formaldehyde by itself did not seem to form any fluorescent adducts with the bovine RNase.

\section{Discussion}

The results clearly indicate that aminoguanidine is a potent, irreversible inhibitor of human and rat SSAO both in vitro and in vivo. SSAO is a copper-dependent enzyme and probably possesses a 6-hydroxydopa (or pyridoxal, pyrroloquinoline quinone) moiety as cofactor [32]. As indicated in Figure 6 aminoguanidine, as is the case for other hydrazines [33], can react with the 3-keto group of the phenyl ring of 6-hydroxydopa (as well as pyridoxal or pyrroloquinoline quinone groups) and form covalently a hydrazone adduct. The enzyme is therefore irreversibly inactivated by aminoguanidine.

Aminoguanidine blocks advanced protein glycation in vitro [14]. Whether or not this drug also inhibits advanced glycation in vivo remains to be clarified. Nevertheless aminoguanidine significantly reduces STZ-induced albuminuria [19], regional albumin clearance [20], lipid peroxidation in vivo [16], and it retards the development of experimental diabetic nephropathy [15]. These studies not only indicate

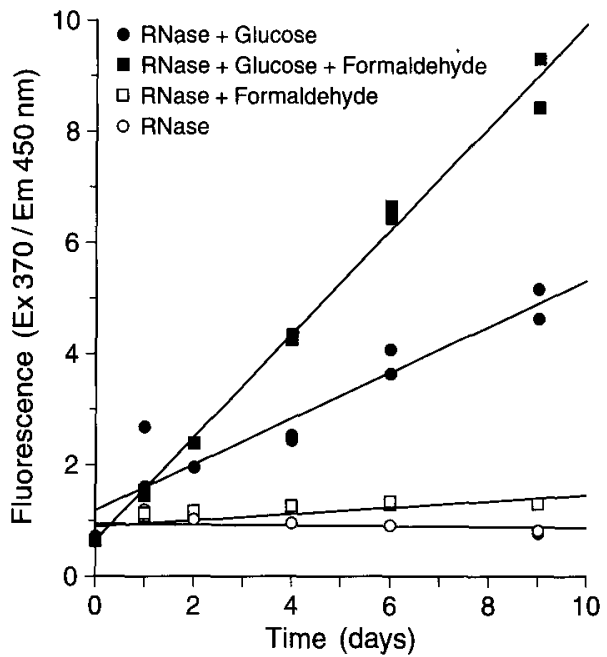

Fig.5. Effect of formaldehyde on advanced glycation of bovine RNase in vitro. RNase $(20 \mathrm{mg} / \mathrm{ml})$ was incubated with glucose $(0.5 \mathrm{~mol} / \mathrm{l})$ in the presence or absence of formaldehyde $(0.008 \%)$ at $37^{\circ} \mathrm{C}$. Florescence $(\mathrm{Ex} 370 / \mathrm{Em} 450 \mathrm{~nm})$ was measured at different time period. Results are of duplicate experiments

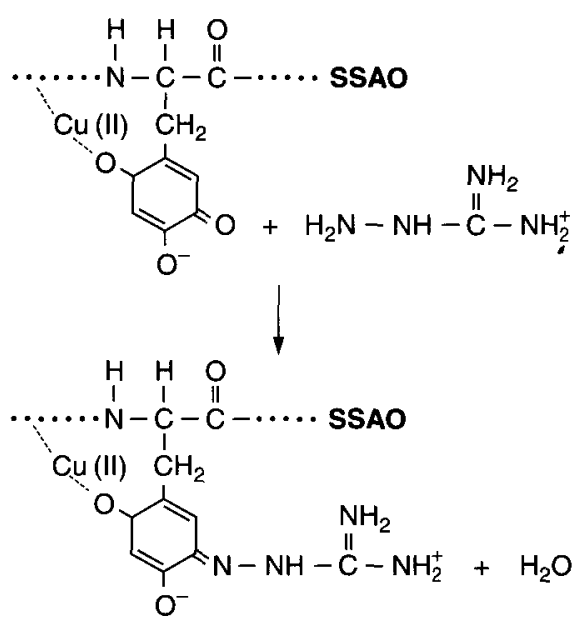

Fig. 6. Scheme showing that aminoguanidine, as with other hydrazines, can react with the 3-keto group of the phenyl ring of 6-hydroxydopa and form covalently a hydrazone adduct

the importance of the formation of AGEs in the aetiology of complications associated with diabetes, but also indicate that the prevention of the formation of AGEs may be a useful way of ameliorating diabetic complications. In these in vivo studies multiple daily doses of aminoguanidine (i.e. from 25 to $50 \mathrm{mg} / \mathrm{kg}$ ) were used $[15,16,18-20,34]$. We have shown that a single dose of aminoguanidine $(10 \mathrm{mg} / \mathrm{kg})$ almost completely blocks aorta and partially blocks kidney SSAO activity in rats. There is little doubt that the multiple large doses of aminoguanidine, that were employed in those previous studies, would effectively inhibit SSAO activity. We have shown that aminoguanidine administered chronically caused a substantially 
greater increase of methylamine excretion, a typical SSAO substrate (Fig. 4) than a single acute treatment. A complete inhibition of SSAO activity was detected after such chronic treatment (results not shown).

Aminoguanidine has also been found to inhibit nitric oxide synthase [35]. Nitric oxide production seems to be involved in the pathogenesis of early diabetic vascular dysfunction and inhibition of its activity by aminoguanidine was proposed to be related to the prevention of AGE formation [36]. The in vivo effects of aminoguanidine seem to be more complicated than simply preventing direct chemical glycation. Aminoguanidine has been widely used as a diamine oxidase inhibitor [37]. This is an important enzyme regulating polyamine homeostasis and related to several important physiological functions [38]. Aminoguanidine, a reactive hydrazine, seems capable of reacting with pyridoxal phosphate or the pyridoxal enzymes and form hydrazone adducts. Hydrazine derivatives also form DNA adducts [39] and have been claimed to be carcinogenic and genotoxic to the liver and other tissues [40]. The potential secondary effects of any hydrazine drugs should not be totally ignored.

It is interesting to note that in diabetes not only is plasma SSAO activity increased [24-28], but it also positively correlates with plasma glycated haemoglobin and urinary albumin excretion [26]. Our findings that MDL-72974A, a selective non-hydrazine SSAO inhibitor, reduces urinary LDH excretion (a nephropathy indicator) in STZ-induced diabetic rats and that aminoguanidine strongly inhibits SSAO activity in vivo, suggest that SSAO-catalysed deamination may be related to some of the diabetic complications, such as nephropathy. Unfortunately this study was complicated due to the effect of MDL-72974A on the urinary LDH excretion.

The apparent increase of protein glycation by formaldehyde at low concentration in vitro (Fig. 5) also suggests the involvement of SSAO-mediated deamination in the formation of AGEs. The mechanism of the formaldehyde effect on protein glycation remains to be explored. Formaldehyde by itself is a well-known protein fixation agent, which is capable of inducing protein crosslinking due to formation of methylene bridges of proteins and thus inducing modification of important structural and functional proteins. The increased production of formaldehyde in the blood from deamination of methylamine could be an alternative mode of increasing blood vessel hardening, which is considered to be a major problem associated with diabetic complication and aging. Interestingly aldehyde dehydrogenase is known to be absent in the plasma [41], therefore, formaldehyde generated in the blood could not be quickly detoxified.

Advanced glycation is an oxidative process in which free radicals are involved [3-6]. In fact, diabetes has been considered to be a state of increased oxidative stress (a disturbance of balance between oxidative stress factors and antioxidant factors in favour of the former) [4]. Increases in the levels of circulating lipid peroxides [42], conjugated dienes [43], and malonaldehyde [16] have been found to be associated with diabetic atherosclerosis. This hypothesis has been confirmed in a recent finding that hydroxyl free radical is increased in blood and tissues in STZinduced diabetic rats [44]. It is, however, not yet known what triggers the increase in the oxidative stress in diabetes. The increase in SSAO activity in serum or kidney tissues of diabetic patients and animals [23-28] may relate to this increase in oxidative stress due to excessive deamination. Deamination reactions lead to the production of hydrogen peroxide, which is in turn converted to toxic hydroxyl free radicals via the Fenten reaction in the presence of transition metals [45]. It is interesting to note that SSAO is selectively located in vascular smooth muscles [46, 47], cartilage [48] and the retina [49] and also circulates in the blood [23-28]. These tissues are known to be vulnerable to glycation and damage in diabetic patients.

SSAO catalyses the deamination of endogenous alkylamines, such as methylamine $[21,22]$ and aminoacetone [50]; toxic formaldehyde and methylglyoxal are produced respectively. SSAO-mediated deamination of methylamine has been demonstrated to be cytotoxic to endothelial cells in vitro [29]. It was also observed that formaldehyde, derived from deamination of methylamine, forms macromolecular adducts and induces protein cross-linking in vivo [51]. It is intriguing that urinary methylamine excretion is enhanced in the diabetic rats (Fig. 4). This observation is in fact consistent with a classic 1935 report [52]. In this study only three patients were analysed with a rather primitive method. We found approximately twofold increase of urinary methylamine in the diabetic rats, when SSAO activity was blocked by chronic administration of aminoguanidine. If SSAO activity was not blocked, methylamine would be quickly metabolized. The increase of methylamine metabolism in the diabetic rats was less clearly evident. It is possible that the increased SSAO activity in the diabetes may be a result of up-regulation due to increase of SSAO substrates, i.e. methylamine or aminoacetone. It remains to be established how methylamine is increased in diabetes.

Blood methylglyoxal level was found to be significantly increased in diabetic patients [53]. This active endogenous aldehyde also binds and modifies proteins under physiological conditions [54] and has been considered to be cytotoxic and related to diabetic complications [55]. Aminoguanidine prevents diabetes-induced arterial wall protein crosslinking [56] and reduces diabetic nephropathy [15]. Aminoguanidine reacts with methylglyoxal under physiological 
conditions [57]. It seems to be reasonable to propose that aminoguanidine can also chemically react with and detoxify toxic aldehydes.

In conclusion excessive SSAO-mediated deamination, i. e. in diabetes, would increase the production of toxic aldehydes, such as formaldehyde and methylglyoxal, and enhance oxidative stress, which are in favour of induction of advanced protein glycation. Aminoguanidine can effectively block SSAO activity and/or react with the toxic aldehyde products. This may be, at least partly, related to the reduction of diabetic experimental albuminuria and nephropathy. More investigation is required to substantiate this hypothesis.

Acknowledgements. We are grateful to the Medical Research Council of Canada, the Canadian Diabetes Association and Saskatchewan Health for financial support, and Dianne Young and Keith Jay for technical assistance.

\section{References}

1. Brownlee M, Cerami A, Vlassara H (1988) Advanced glycosylation end products in tissue and the biochemical basis of diabetic complications. N Engl J Med 318: 1315-1321

2. Brownlee M (1992) Non-enzymatic glycosylation of macromolecules: prospects of pharmacological modulation. Diabetes 41[Suppl 2]: 57-60

3. Fu MX, Knecht KJ, Thorpe SR, Baynes JW (1992) Role of oxygen in cross linking and chemical modification of collagen by glucose. Diabetes 41[Suppl 2]: 42-48

4. Baynes JW (1991) Role of oxidated stress in development of complications in diabetes. Diabetes 40: 405-412

5. Hunt JV, Bottoms MA, Mitchinson MJ (1993) Oxidative alteration in the experimental glycation model of diabetes mellitus are due to protein-glucose adduct oxidation. Biochem J 291: 529-535

6. Hunt JV, Smith CCT, Wolff SP (1990) Autooxidative glycosylation and possible involvement of peroxides and free radicals in LDL modification by glucose. Diabetes 39: 1420-1424

7. Monnier VM, Kohn RR, Cerami A (1984) Accelerated age related browning of human collagen in diabetes mellitus. Proc Natl Acad Sci USA 81: 583-587

8. Lo SK, Janakidevi K, Lai L, Malik AB (1993) Hydrogen peroxide-induced increase in endothelial adhesiveness is dependent on ICAM-1 activation. Am J Physiol 264: L406-L412

9. Uusitupa MIJ, Niskanen LK, Sittonen O, Voutilainen E, Pyorala K (1993) Ten-year cardiovascular mortality in relation to risk factors and abnormalities in lipoprotein composition in type 2 (non-insulin-dependent) diabetic and nondiabetic subjects. Diabetologia 36: 1175-1184

10. Brownlee M (1985) Microvascular disease and related abnormalities: Their relation to control of diabetes. In: Marble A et al. (eds) Joslin's diabetes mellitus. Lea \& Febiger, Philadelphia pp 185-216

11. Mullarkey CJ, Edelstein D, Brownlee M (1990) Free radical generation by early glycation products: a mechanism for accelerated atherogenesis in diabetes. Biochem Biophys Res Comm 173: 932-939

12. Brett J, Ogawa S, Kirstein M, Radoff S, Vlassara H, Stern D (1990) Advanced glycosylation end products selectively attract monocytes to migrate across endothelial cell monolayers and induce activation and growth factor elaboration. Circulation 82[Suppl 3]: 92 (Abstract)

13. Vlassara H, Makita Z, Rayfield E, Freidman E, Cerami A, Morgelo S (1990) In vitro advanced glycation as a signal for monocyte migration in vessel wall: role in diabetes and aging. Circulation 82[Suppl 3]: 92 (Abstract)

14. Edelstein D, Brownlee M (1992) Mechanistic studies of advanced glycosylation end product inhibition by aminoguanidine. Diabetes 41: 26-29

15. Soulis-Liparota T, Cooper M, Papazoglou D, Clarke B, Jerums G (1991) Retardation by aminoguanidine of development of albuminuria, mesangial expansion and tissue fluorescence in streptozotocin induced diabetic rats. Diabetes 40: 1328-1335

16. Bucala R, Makita Z, Koschinsky T, Cerami A, Vlassara H (1993) Lipid advanced glycation: pathway for lipid oxidation in vivo. Proc Natl Acad Sci USA 90: 6434-6438

17. Picard S, Parathasarathy S, Fruebis J, Witzum JL (1992) Aminoguanidine inhibits oxidative modification of low density lipoprotein and the subsequent increase in uptake by macrophage scavenger receptors. Proc Natl Acad Sci USA 89: 6876-6880

18. O'Brien RE, Panangiotopoulos S, Cooper MS, Jerums G (1992) Anti-atherogenic effect of aminoguanidine, an inhibitor of advanced glycation. Diabetes 4[Suppl 1] 16A (Abstract)

19. Itakura M, Yoshikawa H, Bannai C et al. (1992) Aminoguanidine decreases urinary albumin and high-molecular weight proteins in diabetic rats. Life Sci 49:889-897

20. Huijiberts MSP, Wolffenbuttel BHR, Crijns FRL et al. (1994) Aminoguanidine reduces regional albumin clearance but not urinary albumin excretion in streptozotocindiabetic rats. Diabetologia 37: 10-14

21. Yu PH (1990) Oxidative deamination of aliphatic amines by rat aorta semicarbazide-sensitive amine oxidase. J Pharm Pharmacol 42: 882-884

22. Boor PJ, Trent MB, Lyles GA, Tao M, Ansari GAS (1992) Methylamine metabolism to formaldehyde by vascular semicarbazide-sensitive amine oxidase. Toxicology 73 : 251-258

23. McEwen CM Jr, Castell DO (1967) Abnormalities of serum monoamine oxidase in chronic liver disease. $J$ Lab Clin Med 70: 36-47

24. Nilsson SE, Tryding N, Tufvesson G (1968) Serum monoamine oxidase in diabetes mellitus and some other internal diseases. Acta Med Scand 184: 105-108

25. Tryding N, Nilsson SE, Tufvesson G et al. (1969) Physiological and pathological influences on serum monoamine oxidase level. Scan J Clin Lab Invest 23: 79-84

26. Boomsma F, Derkx FHM, van den Meiracker AH, Veld AJM, Schalekamp MADH (1995) Plasma semicarbazidesensitive amine oxidase activity is elevated in diabetes mellitus and correlates with glycosylated haemoglobin. Clin Sci 88: 675-679

27. Hayes BE, Clarke DE (1990) Semicarbazide-sensitive amine oxidase activity in streptozotocin diabetic rats. Res Comm Chem Pathol Pharmacol 69: 71-83

28. Elliott J, Fowden AL, Callingham BA, Sharman DF, Silver M (1991) Physiological and pathological influences on sheep blood plasma amine oxidase: effect of pregnancy and experimental alloxan-induced diabetes mellitus. Res Vet Science 50: 334-339

29. Yu PH, Zuo DM (1993) Methylamine, a potential endogenous toxin for vascular tissues: formation of formaldehyde via enzymatic deamination and the cytotoxic effects on endothelial cells. Diabetes 42: 594-603 
30. Yu PH, Zuo DM (1991) (E)-4-Fluoro-beta-fluoroethylene benzene butamine (MDL-72974A) as highly potent inhibitor for semicarbazide-sensitive amine oxidase from vascular tissues and serum of different species. Biochem Pharmacol 43: 307-312

31. Chouinard S, Viau C (1992) Reversibility of renal tubular dysfunction in streptozotocin-induced diabetes in the rat. Can J Physiol Pharmacol 70: 977-982

32. Jane SM, Mu D, Wemmer D et al. (1990) A new redox cofactor in eukaryotic enzymes: 6-hydroxydopa at the active site of bovine serum amine oxidase. Science 248: 981987

33. Jane SM, Klinman JP (1991) An investigation of bovine serum amine oxidase active site stoichiometry: evidence for an aminotransferase mechanism involving two carbonyl cofactors per enzyme dimer. Am Chem Soc 30: 4599-4605

34. Nicholis K, Mandel TE (1989) Advanced glycosylation end-products in experimental murine diabetic nephropathy: effect of islet isografting and of aminoguanidine. Lab Invest 60: 486-491

35. Corbett JA, Tilton RG, Chang K et al. (1992) Aminoguanidine, a novel inhibitor of nitric oxide formation, prevents diabetic vascular dysfunction. Diabetes 41: 552-556

36. Tilton RG, Chang K, Hason KS et al. (1993) Prevention of diabetic vascular dysfunction by guanidines; inhibition of nitric oxide synthase versus advanced glycation end-product formation. Diabetes 42: 221-232

37. Tamura H, Horiike K, Fukura H, Watanabe T (1989) Kinetic studies on the inhibition mechanism of diamine oxidase from porcine kidney by aminoguanidine. $\mathrm{J}$ Biochem (Tokyo) 105: 299-306

38. Seiler N (1995) Polyamine oxidase, properties and functions. Prog Brain Res 106: 333-344

39. Mathison BH, Murphy SE, Shank R (1994) Hydralazine and other hydrazine derivatives and the formation of DNA adducts. Toxicol Appl Pharmacol 127: 91-98

40. Bosan WS, Shank RC, MacEven JD, Gaworske CL, Newberne PM (1987) Methylation of DNA guanine during the course of induction of liver cancer in hamsters by hydrazine or dimethylnitrosamine. Carcinogenesis 8: 439-444

41. Helander A, Tottmar O (1987) Metabolism of biogenic aldehydes in isolated human blood cells, platelets and in plasma. Biochem Pharmacol 36: 1077-1082

42. Sato Y, Hotta N, Sakamonto N, Matsuoka S, Ohishin N, Yagi IK (1979) Lipid peroxide levels in plasma of diabetic patients. Biochem Med 21: 104-107

43. Jennings PE, Jones AF, Florkouski CM, Lunic J, Barnett $\mathrm{AH}$ (1987) Increased diene conjugates in diabetic subjects with microangiopathy. Diabet Med 4: 452-456
44. Ohkuwa T, Sato Y, Naoi M (1995) Hydroxyl radical formation in diabetic rats induced by streptozotocin. Life Sci 56: 1789-1798

45. Gutteridge JMC (1994) Hydroxyl radicals, iron, oxidative stress and neurodegeneration. Ann N Y Acad Sci 738: 201-213

46. Lyles GA, Singh I (1985) Vascular smooth muscle cells: a major source of the semicarbazide-sensitive amine oxidase of the rat aorta. J Pharm Pharmacol 37: 637-643

47. Wibo M, Duong AT, Godfraind T (1980) Subcellular location of semicarbazide-sensitive amine oxidase in rat aorta. Eur J Biochem 112: 87-94

48. Lyles GA, Bertie KH (1987) Properties of a semicarbazidesensitive amine oxidase in rat articular cartilage. Pharmacol Toxicol [Suppl] 1: 33

49. Zuo, DM, Yu, PH (1993) Semicarbazide-sensitive amine oxidase and monoamine oxidase in rat brain microvessels, meninges, retina and eye sclera. Brain Research Bull 33: 307-311

50. Lyles GA, Chalmers J (1992) The metabolism of aminoacetone to methylglyoxal by semicarbazide-sensitive amine oxidase in human umbilical artery. Biochem Pharmacol 31: $1417-1424$

51. Yu PH, Zuo DM (1995) Formaldehyde produced endogenously via deamination of methylamine; a potential risk factor for initiation of endothelial injury. Atherosclerosis 120: $189-197$

52. Kapeller-Adler R, Toda K (1932) Über das Vorkommen von Monomethylamine im Harn. Biochem Zeischrift 248: $403-425$

53. McLellan AC, Phillips SA, Thornalley PJ (1992) The assay of methylglyoxal in biological systems by derivatization with 1,2-diamino-4,5-dimethoxybenzene. Anal Biochem 206: 17-23

54. Lo TWC, Westwood ME, McLellan AC Selwood T, Thornalley PJ (1994) Binding and modification of proteins by methylglyoxal and physiological conditions. J Biol Chem 269: 32299-32305

55. Thornalley PJ (1990) The glyoxalase system: new developments towards functional characterization of a metabolic pathway fundamental to biological life. Biochem J 269: 111

56. Brownlee $M$, Vlassara $H$, Kooney $P$, Ulrich $P$, Cerai A (1986) Aminoguanidine prevents diabetes-induced arterial wall protein cross-linking. Science 232: 1629-1632

57. Lo TWC, Selwood T, Thornalley PJ (1994) The reaction of methylglyoxal with aminoguanidine under physiological conditions and prevention of methylglyoxal binding to plasma proteins. Biochem Pharmacol 48: 1865-1870 